\title{
Dry Reforming of Methane with Ni Supported on Mechanically Mixed Yttria-Zirconia Support
}

\author{
Ahmed Aidid Ibrahim ${ }^{1}$ - Samsudeen Olajide Kasim ${ }^{1}$. Anis Hamza Fakeeha ${ }^{1}$. Mahmud Sofiu Lanre ${ }^{1}$. \\ Ahmed Elhag Abasaeed ${ }^{1}$. Jehad K. Abu-Dahrieh ${ }^{2}$. Ahmed Sadeq Al-Fatesh ${ }^{1}$
}

Received: 15 November 2021 / Accepted: 30 January 2022 / Published online: 7 February 2022

(c) The Author(s) 2022

\begin{abstract}
This study focuses on $\mathrm{CH}_{4}$ reforming with $\mathrm{CO}_{2}$ over $\mathrm{Ni}$ supported on yttria mixed with zirconia support. Different loading of yttria was used to enhance the performance of $\mathrm{Ni}$ towards achieving the optimum activity. The physicochemical properties of both fresh calcined and used catalysts were studied using a range of characterization techniques. The specific surface area measurement by the BET method showed a progressive increase in the area with an increase in yttria loading. The monoclinic $\left(m-\mathrm{ZrO}_{2}\right)$ and tetragonal $\left(t-\mathrm{ZrO}_{2}\right)$ phases were identified on all the samples by the XRD analysis. A reduction in the intensity of $m-\mathrm{ZrO}_{2}$ was observed on adding $\mathrm{Ni}$ to the catalysts while the diffraction pattern of crystalline yttria was not identified. The reducibility analysis showed the influence of yttria. It induces the formation of $\mathrm{NiYO}_{3}$ species with stronger active metal-support interaction. From the catalytic test, $5 \mathrm{Ni} / 10 \mathrm{Y}-\mathrm{Z}-3215$ had the highest feed conversion of about 68 and $88 \%$ for $\mathrm{CH}_{4}$ and $\mathrm{CO}_{2}$ respectively. The TEM analysis showed a uniform dispersion of $\mathrm{NiO}$ particles over the mixed yttriazirconia support with no agglomeration of the active metal particles after the reaction. The measurement of the quantity of carbon deposits by the TGA revealed that the increase in yttria loading enhanced the gasification of carbon deposits with $5 \mathrm{Ni} / 20 \mathrm{Y}-\mathrm{Z}-3215$ recording the lowest weight loss of about $28 \%$.
\end{abstract}

\section{Graphical Abstract}

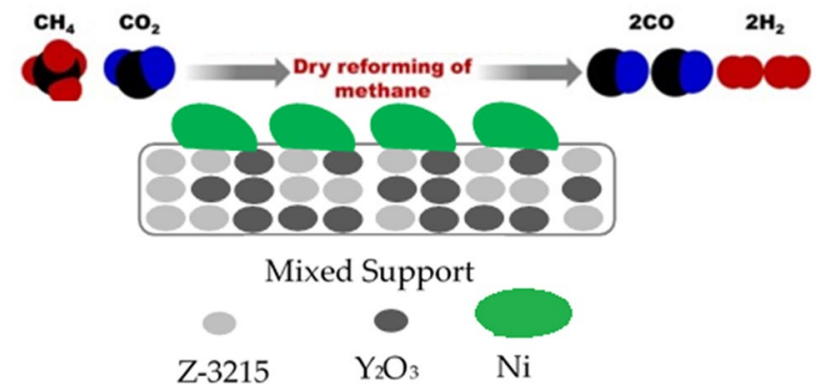

Keywords Diffusion $\cdot$ Shift reaction $\cdot$ Reforming $\cdot$ Monoclinic $\cdot$ Tetragonal $\cdot$ Metal oxide $\cdot$ Mixed support

Jehad K. Abu-Dahrieh

j.abudahrieh@qub.ac.uk

$\bowtie$ Ahmed Sadeq Al-Fatesh aalfatesh@ksu.edu.sa

1 Chemical Engineering Department, College of Engineering, King Saud University, P.O. Box 800, Riyadh 11421, Saudi Arabia

2 School of Chemistry and Chemical Engineering, Queen's University Belfast, Belfast BT9 5AG, Northern Ireland, UK

\section{Introduction}

The reduction of greenhouse gas (GHG) emissions is arguably one of the reigning topics of discussion in the field of catalysis. Dry reforming of methane happens to be one of the ways by which this could be achieved. It involves a reaction between methane $\left(\mathrm{CH}_{4}\right)$ and carbon dioxide $\left(\mathrm{CO}_{2}\right)$ as written in Eq. (1). 
$\mathrm{CH}_{4}+\mathrm{CO}_{2} \leftrightarrow 2 \mathrm{H}_{2}+2 \mathrm{CO} \quad \Delta H=247 \mathrm{~kJ} \mathrm{~mol}^{-1}$

This reaction leads to the consumption of the GHG to yield valuable products, a mixture of $\mathrm{H}_{2}$ and $\mathrm{CO}$, well known as syngas [1]. Using the appropriate combining ratio by the Fischer-Tropsch process, the syngas could be used to manufacture varieties of value-added chemicals including dimethyl ether, olefins and a host of others [2]. Despite how promising dry reforming of methane may look, the reaction has yet to be commercialized owing to challenges that are connected to the catalysts in terms of their performance and economy [3]. Steam reforming of methane is another way by which $\mathrm{CH}_{4}$ could be used to produce hydrogen; however, this reaction only involves the consumption of $\mathrm{CH}_{4}$ while $\mathrm{CO}_{2}$ is being left out. To solve the challenges associated with the $\mathrm{CH}_{4}$ reforming with $\mathrm{CO}_{2}$, researchers have come up with a number of approaches.

Higher temperature is required to achieve significant conversions in dry reforming of $\mathrm{CH}_{4}$ because of the endothermic nature of the reaction. In light of that, noble metals (platinum, rhodium, and ruthenium) could be used as catalysts because of their high performance and less vulnerability to coke formation and sintering [4]. However, catalysts synthesized using these precious metals cannot be commercialized because of their limited availability and cost $[5,6]$. Alternatives to these expensive, scarce, precious-metal-based catalysts are Ni-supported catalysts [6-8]. On the one hand, Ni is cheap and abundant, in addition to that, its use in catalytic dry reforming of methane reactions has shown promising results. On the other hand, at the temperature that is thermodynamically favourable for $\mathrm{CH}_{4}$ reforming with $\mathrm{CO}_{2}$, Ni particles become sintered due to its low Tammann temperature. Also, carbon deposition that usually accompanies dry reforming reactions makes $\mathrm{Ni}$ susceptible to deactivation [9]. Owing to that, it has become necessary to consolidate $\mathrm{Ni}$ particles to make them less prone to deactivation in reforming reactions. Reduction of metal domain size to the minimum possible, the use of molecular layer deposition, Ni precursor in perovskites, and other different approaches have been explored towards achieving this [10-13]. Furthermore, the use of metal oxides as supports is another promising alternative that could supposedly improve the interaction between the active metal phase and the supports [12]. In the case of reducible oxides (e.g., $\mathrm{CeO}_{2}, \mathrm{ZrO}_{2}$ ), the supports partially transfer oxygen to or from the metal particles as demonstrated by $\mathrm{CeO}_{2}$-supported catalysts in $\mathrm{CO}_{2}$ and steam reforming of $\mathrm{CH}_{4}[14,15]$. It has been observed that the reduced ceria could be oxidized by $\mathrm{CO}_{2}$ or steam and the oxidized $\mathrm{CeO}_{2}$ then transfers its oxygen to the metal to become reduced again [16]. On the one hand, the effect of using oxide supports could be greatly influenced by decreasing the size of the catalysts which consequently strengthens the metal's interaction with the support and influences the activity of the catalysts [17]. On the other hand, such strong interaction may be a disadvantage to the catalyst due to the overgrowth of the reducible oxide support on top of the metal particles rendering access to the active metal sites almost impossible. This usually occurs under reducing agent atmosphere and $\mathrm{CH}_{4}$ reforming reaction conditions [18]. A typical occurrence has been reported by Tauster et al. in their study where the overgrowth of titania on Pd catalyst lowered the metal's dispersion without sintering of Pd particles [19]. This phenomenon is well known as strong metal-support interaction. Thus, understanding the metal-oxide interaction and being able to manipulate it would offer a greater opportunity to enhance the performance of the catalyst. Different methods of stabilizing Ni on metaloxide supports exist. These are not limited to impregnating Ni particles within well-defined pores of the support, the use of mixed metal-oxides as supports and the use of surface phase oxide [20, 21]. Supports interact with the active metal and alter the mechanism of carbon deposition[22]. $\mathrm{ZrO}_{2}$ with Lewis basicity is sorted among the prime supports to hinder carbon formation. as confirmed by the study of Yamazaki et al. [23]. The $\mathrm{ZrO}_{2}$ support has numerous morphologies of zirconia that could display diverse $\mathrm{O}_{2}$ mobility and different strengths of the metal-support interactions. These properties of zirconia could modify the thermal sintering of active metal particles and the removal of coke on the surface of the catalyst. The $\mathrm{ZrO}_{2}$ phase change can be stopped by adding a certain amount of metal oxides such as $\mathrm{Y}_{2} \mathrm{O}_{3}$, or $\mathrm{CeO}_{2}$ into zirconia. The addition of yttria vigorously stabilized the cubic $\mathrm{ZrO}_{2}$ relative to monoclinic and tetragonal $\mathrm{ZrO}_{2}$ [24]. Bahari et al.; investigated the impact of $\mathrm{Y}_{2} \mathrm{O}_{3}$ doping toward dry reforming of methane over $\mathrm{Co} /$ mesoporous alumina $\left(\mathrm{Co} / \mathrm{m}-\mathrm{Al}_{2} \mathrm{O}_{3}\right)$ catalyst [25]. Their result exhibited that the $\mathrm{Co}$ particle dispersion on $\mathrm{m}-\mathrm{Al}_{2} \mathrm{O}_{3}$ was distinctly improved after $\mathrm{Y}_{2} \mathrm{O}_{3}$ blend, resulting in lesser crystallite size and negligible $\mathrm{Co}$ agglomeration. In addition, the $\mathrm{Y}_{2} \mathrm{O}_{3}$ lowered catalyst reducibility by strengthening the $\mathrm{m}-\mathrm{Al}_{2} \mathrm{O}_{3}$ interaction.

Wang et al. reported a better activity and stability in their study when Ni supported on gamma-alumina were mixed with yttria [26]. In this work, yttria was mechanically mixed with zirconia, an underlying support, to tune the interaction of Ni with these supports. Different loadings of yttria were used and the optimum percentage was determined. The zirconia employed in this study differs from others that have been reported in the literature in terms of the average particle size and specific surface area, as reported by the manufacturer and we opine that these differences might be as a result of its preparation. 


\section{Experimental}

\subsection{Materials}

Active metal precursor nickel (II) nitrate hexahydrate $\left[\mathrm{Ni}\left(\mathrm{NO}_{3}\right)_{2} \cdot 6 \mathrm{H}_{2} \mathrm{O} ; 98 \%\right.$, Alfa Aesar] and the support yttrium oxide nano-powder $\left(\mathrm{Y}_{2} \mathrm{O}_{3}\right)$ were procured from Riedel-De Haen AG, Seezle, Germany and mkNANO respectively. The zirconia, Z-3215, was gifted to us by Daiichi Kigenso Kagaku Kogyo Co., Ltd. Osaka - Japan.

\subsection{Catalyst Preparation}

Herein, the preparation falls under two categories which encompass support preparation and the subsequent impregnation of the active metal in the mixed support.

Yttrium oxide nano-powder at different percentages $(5$, 10,15 and $20 \% \mathrm{wt}$ ) was mixed mechanically with zirconia to obtain mixed support (Y-Zr). A predetermined amount of $\mathrm{Ni}\left(\mathrm{NO}_{3}\right)_{2} \cdot 6 \mathrm{H}_{2} \mathrm{O}$ equivalent to $5.0 \mathrm{wt}$. \% loading of nickel oxide was dissolved in an aqueous medium, stirred and thereafter $\mathrm{Y}-\mathrm{Zr}$ was added. Stirring was done over a magnetic heater at $80^{\circ} \mathrm{C}$ until a slurry was obtained. Subsequently, the slurry was positioned in a furnace for drying at $120^{\circ} \mathrm{C}$ overnight. The dried samples were then calcined in air at $700{ }^{\circ} \mathrm{C}$ for $3 \mathrm{~h}$. The synthesized samples are labelled as 5Ni-xY-Z-3215 (where $\mathrm{x}$ could be $0,5,10,15$ and 20).

\subsection{Catalyst Evaluation}

The reaction of methane with $\mathrm{CO}_{2}$ was performed using $5 \mathrm{Ni}$ $\mathrm{xY}-\mathrm{Z}-3215$ under atmospheric condition and at $700{ }^{\circ} \mathrm{C}$ in a stainless steel, vertically fixed tubular reactor (PID Eng. \& Tech Micro Activity Reference, $9.1 \mathrm{~mm}$ i.d. and $30 \mathrm{~cm}$ long). Testing was done with $100 \mathrm{mg}$ of the catalyst that was well placed over glass wool. A K-type stainless sheathed thermocouple was used to monitor the temperature of the reactor. This was positioned axially at the centre of the catalyst bed. Prior to the tests, samples were reduced at a temperature of $700{ }^{\circ} \mathrm{C}$ in the atmosphere of hydrogen gas $(20 \mathrm{ml} / \mathrm{min})$ for $60 \mathrm{~min}$. A volume ratio of 3:3:1 was adopted for the feed gas mixture $\mathrm{CH}_{4}: \mathrm{CO}_{2}: \mathrm{N}_{2}$ with an overall volumetric flow rate of $70 \mathrm{ml}$. $\mathrm{min}^{-1}$ and gas space of 42,000 ml(h.gcat) ${ }^{-1}$. A gas chromatography (Shimadzu GC 2014) with a thermal conductivity detector (TCD) was used to analyse the product stream. Conversions of $\mathrm{CH}_{4}$ and $\mathrm{CO}_{2}$ were evaluated using the following expressions:

$\mathrm{CH}_{4}$ conversion $(\%)=\frac{\mathrm{CH}_{4} \text { in }-\mathrm{CH}_{4} \text { out }}{\mathrm{CH}_{4} \text { in }} \times 100$
$\mathrm{CO}_{2}$ conversion $(\%)=\frac{\mathrm{CO}_{2} \text { in }-\mathrm{CO}_{2} \text { out }}{\mathrm{CO}_{2} \text { in }} \times 100$

\subsection{Catalyst Characterization}

\subsubsection{Surface Area Analysis}

Micromeritics Tristar II 3020 porosity and surface area analyser was employed to achieve the Brunauer-Emmett-Teller (BET) surface area measurement of the catalysts as well as the support using $\mathrm{N}_{2}$ adsorption-desorption isotherm data obtained at liquid nitrogen temperature. At first, the samples were outgassed at $493 \mathrm{~K}$ for $3 \mathrm{~h}$. This ultimately led to the removal of adsorbed moisture and volatile components. Thereafter, the samples were analysed.

\subsubsection{X-ray Diffraction}

XRD analysis was performed using Rigaku (Miniflex) diffractometer that is equipped with $\mathrm{Cu} \mathrm{K} \alpha$ radiation. The apparatus was operated at $40 \mathrm{kV}$ and $40 \mathrm{~mA}$. The $2 \theta$ scan range of $5^{\circ}-90^{\circ}$ was used at a step of $0.02^{\circ}$. X'pert HighScore Plus software was used to examine the data file of the instrument. Different existing phases were matched with the ICDD (International Centre for Diffraction Data) data bank.

\subsubsection{Temperature Programmed Reduction (TPR)/ Temperature Programmed Desorption (TPD)}

The reduction behaviour of the catalysts as well as their basic strength was studied using Micromeritics Auto Chem II 2920. For this, $70 \mathrm{mg}$ of the sample were poured inside the sample tube holder. As for the TPR, argon at $150^{\circ} \mathrm{C}$ was used to outgas the samples for $60 \mathrm{~min}$, followed by cooling to room temperature. Then the temperature of the furnace was ramped up to $800{ }^{\circ} \mathrm{C}$ at the rate of $10{ }^{\circ} \mathrm{C} /$ minute under the flow of $\mathrm{H}_{2} / \mathrm{Ar}$ mixture. Peaks that can be assigned to $\mathrm{H}_{2}$ consumption were recorded by a detector (TCD). The same approach was adopted for the $\mathrm{CO}_{2}$-TPD except that degassing was done with $\mathrm{He}$ and $10 \% \mathrm{CO}_{2} / \mathrm{He}$ mixture was used for the analysis. The $\mathrm{CO}_{2}$ desorption peaks were recorded against the corresponding temperature by a TCD.

\subsubsection{Transmission Electron Microscope (TEM)}

The shape, morphology, microstructure, and particle size distribution of the catalysts were investigated using the Transmission Electron Microscope (JEOL JEM-2100F, USA). The device was operated at $120 \mathrm{kV}$ accelerating voltages. 
Table $1 \mathrm{~N}_{2}$-physisorption data of the calcined support together with $5 \mathrm{Ni} / \mathrm{xY}$-Z-3215 $(\mathrm{x}=0,5,10,15,20)$

\begin{tabular}{lcll}
\hline Fresh samples & $\begin{array}{l}\text { Specific area } \\
\left(\mathrm{m}^{2} / \mathrm{g}\right)\end{array}$ & $\begin{array}{l}\text { Pore volume } \\
\left(\mathrm{cm}^{3} / \mathrm{g}\right)\end{array}$ & $\begin{array}{l}\text { Pore } \\
\text { diameter } \\
(\mathrm{nm})\end{array}$ \\
\hline $\mathrm{Z}-3215$ & 15.2 & 0.09 & 23.2 \\
$5 \mathrm{Ni} / \mathrm{Z}-3215$ & 9.8 & 0.05 & 24.8 \\
$5 \mathrm{Ni} / 5 \mathrm{Y}-\mathrm{Z}-3215$ & 35.9 & 0.17 & 20.6 \\
$5 \mathrm{Ni} / 10 \mathrm{Y}-\mathrm{Z}-3215$ & 37.9 & 0.16 & 15.6 \\
$5 \mathrm{Ni} / 15 \mathrm{Y}-\mathrm{Z}-3215$ & 43.5 & 0.17 & 15.4 \\
$5 \mathrm{Ni} / 20 \mathrm{Y}-\mathrm{Z}-3215$ & 35.1 & 0.14 & 16.0 \\
\hline
\end{tabular}

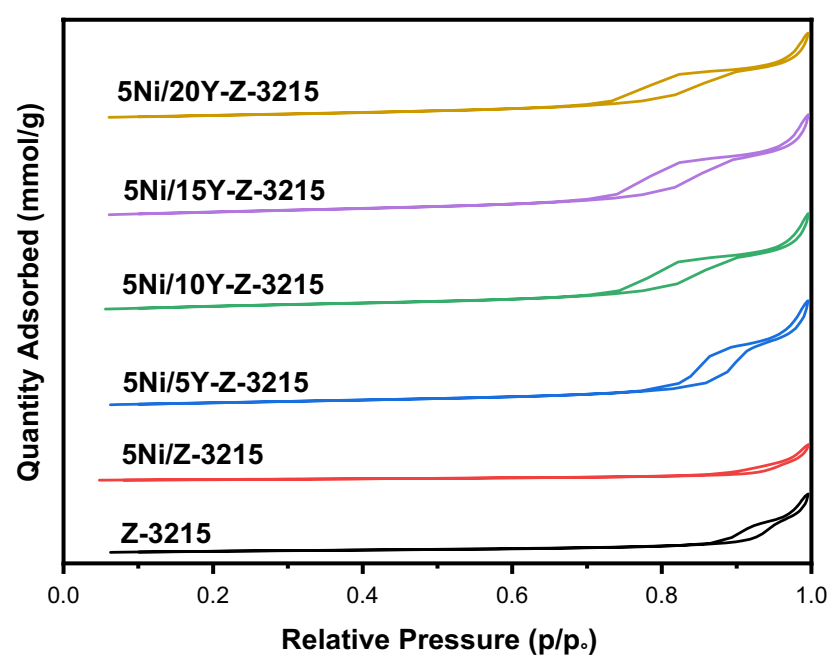

Fig. 1 Surface area and porosity analysis of the calcined support and $5 \mathrm{Ni} / \mathrm{xY}-\mathrm{Z}-3215$ samples

\subsubsection{Thermogravimetric Analysis (TGA)}

Thermal analysis was carried out at the end of the reaction to estimate the quantity of carbon that was deposited on the used catalyst samples. The analysis was performed with a thermogravimetric/differential analyser (Shimadzu TGA). About $10 \mathrm{mg}$ of the samples were heated from room temperature up to $1000{ }^{\circ} \mathrm{C}$ at a heating rate of $20^{\circ} \mathrm{C}$ /minute while the weight change was recorded with the rise in temperature.

\section{Results and Discussion}

\subsection{Surface Area and Porosity Measurement}

The results of the $\mathrm{N}_{2}$ adsorption-desorption analysis are shown in Table 1 and Fig. 1. On the one hand, there is a drastic decrease in the surface area of the support when the active metal was added to it. This is an indication partly that the Ni particles fill up the pores of the support to reduce its surface area. This is also observed for the pore volume. On the other hand, the incorporation of yttria to the zirconia creates an additional surface area for the dispersion of the active metal particles. The area is observed to increase with the yttria loading up to $15 \%$. Above this value, the surface area began to reduce. Similar behaviour was reported by $\mathrm{Hu}$ et al., in their research on hydrogen production using $\mathrm{Ni}$ supported on Y-Zr-O solid solution [27].

The isotherms that are shown in Fig. 1 fall under type IV IUPAC isotherms classification with $\mathrm{H} 4$ hysteresis loop [28]. At low relative pressure the isotherms show monolayer $\mathrm{N}_{2}$ adsorption while at higher relative pressure above 0.7 , multiple layering was observed with gas condensing inside the pores of the samples. This is suggestive of mesoporous material with pore sizes between 2 and $50 \mathrm{~nm}$ [29]. The condensation observed in all the catalysts at relative pressures close to the absolute value represents the condensation within the voids in-between the particles of the catalysts [30]. Additional information about the support, Z-3215, is available in Table $\mathrm{S} 1$ in the supporting information file.

\subsection{X-Ray Diffraction (XRD)}

The results of the XRD diffractogram for the fresh samples are shown in Fig. 2. Both monoclinic $\left(\mathrm{m}-\mathrm{ZrO}_{2}\right)$ and tetragonal $\left(\mathrm{t}-\mathrm{ZrO}_{2}\right)$ zirconia phases are identified on the support and the other samples. $\mathrm{m}-\mathrm{ZrO}_{2}$ appears at $2 \theta$ angles that are equivalent to $28.2,31.5,34.2,34.4,35.3$ and $40.7^{\circ}$, JCPDS 01-081-1314, while the $\mathrm{t}-\mathrm{ZrO}_{2}$ phase can be seen at Bragg angles 29.98, 34.96, 42.88, 50.09, 59.77, 64.53, 74.31 and $82.1^{\circ}$ (JCPDS 01-079-1769) [31]. Upon adding Ni, the intensity of the diffraction peaks for monoclinic zirconia, at 28.2 and $31.5^{\circ}$, drastically reduced while a large part of them was transformed into tetragonal phase, as shown in Fig. 2A. This occurrence shows the influence and dispersion of Ni particles within the phases of this support. Also, peaks that are close to each other in the support are seen to have merged to form peaks having a wide base with relatively higher intensity after adding $\mathrm{Ni}$ and yttria. Peaks that can be assigned to $\mathrm{NiO}$ phases appear at $2 \theta=37.3$ (1 111 l), 43.3 (2 000$)$ and $62.8^{\circ}(220)$ [32]. The diffraction peaks for $\mathrm{NiO}$ phases are not that conspicuous, but among all, the angle for the plane (2 20 ) seems obvious as it overlaps with an m$\mathrm{ZrO}_{2}$ phase in the Ni containing samples. Usually, diffraction peaks that are typical of yttria do appear at Bragg angles 29.3, 33.7 and $48.4^{\circ}$ (JCPDS 083-0927). However, for the yttria containing samples in this study, these characteristic peaks were not detected. It can be inferred that the used yttria lacks the necessary crystallinity i.e., it is amorphous, or the particle size is below the detectable lower limit of the machine. A similar occurrence was reported by Damyanova et al. in their characterization of nickel supported on alumina and yttria modified alumina support [33]. 

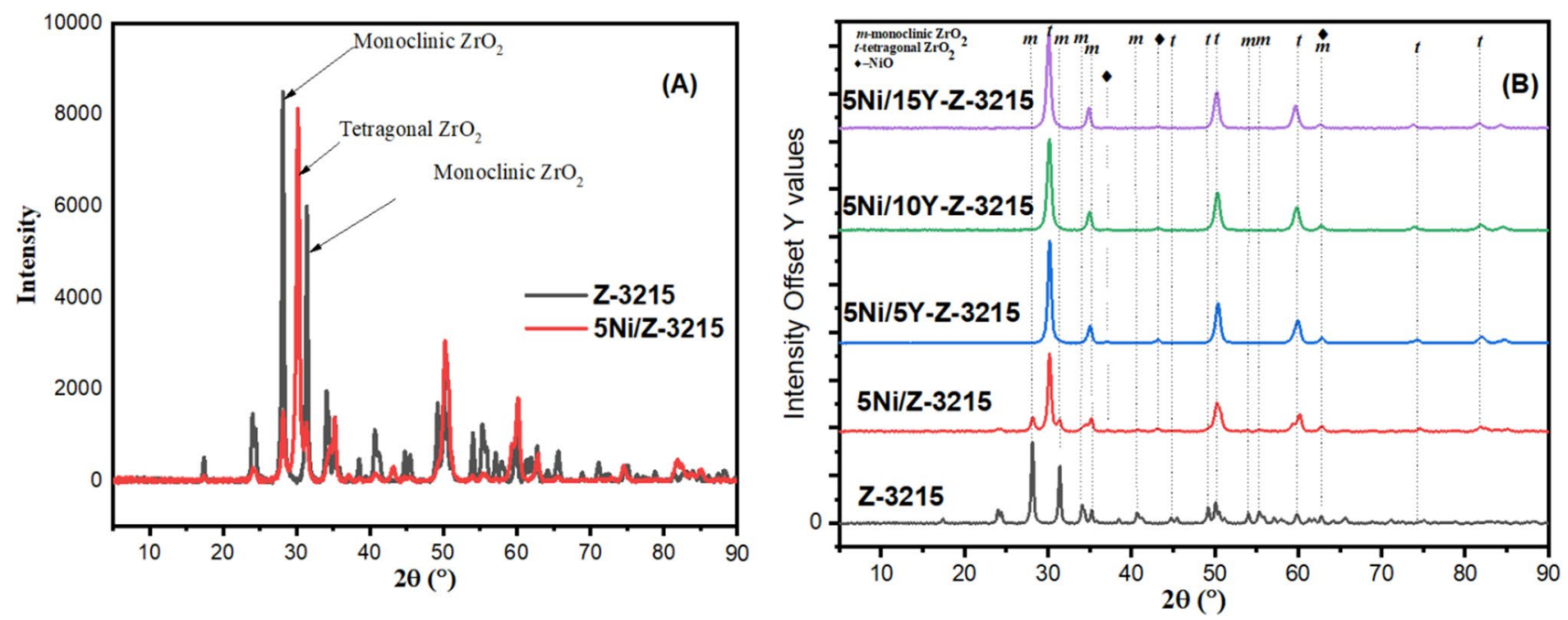

Fig. 2 Powder X-ray diffraction pattern of the fresh samples; Z-3215 and 5Ni-xY-Z-3215 (x being 0, 5, 10, 15)

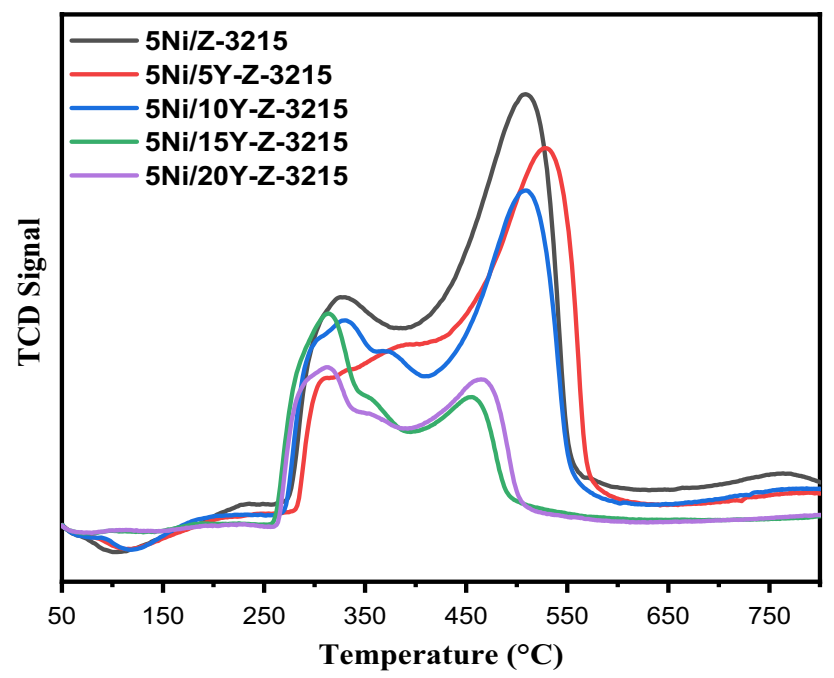

Fig. $3 \mathrm{H}_{2}$-TPR displaying the reduction behaviour of the fresh calcined $5 \mathrm{Ni} / \mathrm{xY}$-Z-3215 $(\mathrm{x}=0,5,10,15$ and 20$)$

\subsection{Temperature Programmed Reduction}

The reducibility of the samples, as well as the interaction of the active metal with the support, was analysed and the results obtained are shown in Fig. 3. From the results, the profile shows that the catalysts are characterized by two reduction peaks and complete reduction occurred at a temperature below $600{ }^{\circ} \mathrm{C}$. The peak at low temperature $\left(325-345{ }^{\circ} \mathrm{C}\right)$ can be related to the reduction of free surface $\mathrm{NiO}$ species, which is in agreement with the reduction of pure $\mathrm{NiO}$ particles [34], while the reduction peak that appeared at high temperature $\left(500-535{ }^{\circ} \mathrm{C}\right)$ can be assigned to the $\mathrm{NiO}$ species that are strongly bonded to the support [35].
On adding yttria, it was observed that there was a progressive decrease in the intensity of the peaks because of the reduction of free $\mathrm{NiO}$ quantity [25] and a slight shift towards the right side of the temperature axis.

This observation is pronounced at higher loading of yttria (i.e., 15 and 20\%). The intensity of $\mathrm{NiO}$ particles at higher temperature is seen to fall below that at temperatures less than $350{ }^{\circ} \mathrm{C}$.

This is an indication that at higher yttria loading larger proportion of $\mathrm{NiO}$ particles have weak interaction with the mixed supports. The closeness of $\mathrm{NiO}$ particles to the yttria could facilitate the formation of $\mathrm{NiYO}_{\mathrm{x}}$-like species at the chosen calcination temperature. It has been proven that $\mathrm{NiYO}_{3}$ species were formed at calcination temperature around $720^{\circ} \mathrm{C}$ due to the diffusion of $\mathrm{NiO}$ particles into the structure of the yttria [26].

\subsection{Temperature Programmed Desorption (TPD)}

The basic sites density and strength within the supports have strong influence on the performance of the catalysts in dry reforming of methane. The different spectra obtained in temperature-programmed desorption analysis fall under different categories depending on the desorption temperature. We have weak basic sites that usually appear within $100-228^{\circ} \mathrm{C}$, sites with medium strength appearing in the range $228-420{ }^{\circ} \mathrm{C}$ and lastly, desorption temperature at $420-500{ }^{\circ} \mathrm{C}$ can be attributed to strong basic sites [33].

The results presented in Fig. 4 shows that the catalysts are characterized by multiple peaks (weak, medium and strong) at different desorption temperatures. Also, an additional weak basic site appeared on all yttria promoted samples at around $145{ }^{\circ} \mathrm{C}$. The yttria promoted catalyst reduced the amount of strong basic sites at $500{ }^{\circ} \mathrm{C}$. All this will surely 


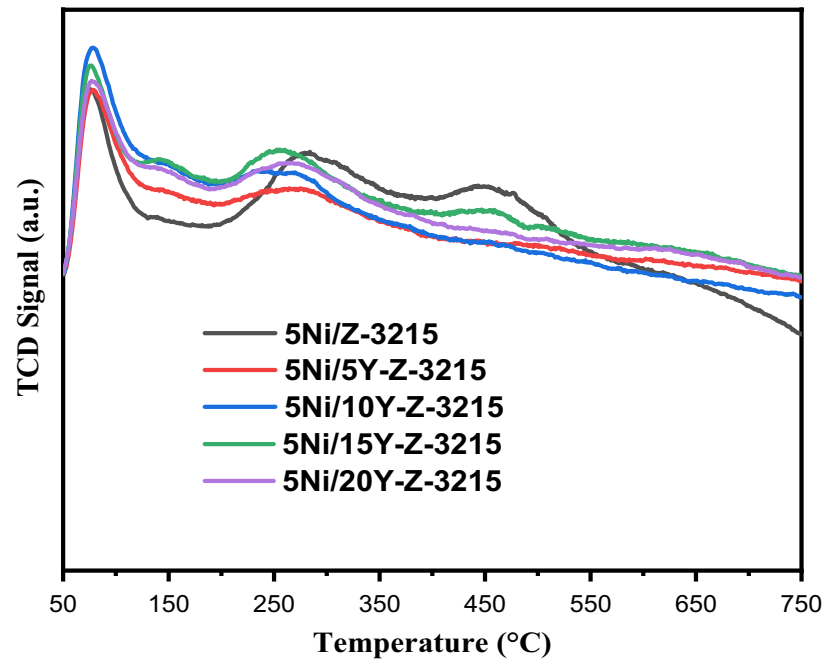

Fig. 4 Temperature controlled $\mathrm{CO}_{2}$ desorption over $5 \mathrm{Ni} / \mathrm{x}-\mathrm{Y}-\mathrm{Z}-3215$ fresh catalyst samples

offer positive contributions to the performance of these catalysts.

\subsection{Catalyst Performance}

The catalysts were tested in a dry reforming reaction after being activated under the flow of $\mathrm{H}_{2} / \mathrm{Ar}$ mixture following the procedure mentioned in Sect. 3.3. We ensured that the system was purged of any unused hydrogen gas before the start of the reaction. The reactions were carried out under the condition outlined in Sect. 3.2 while the evaluation of the catalysts was based on the feed conversions using Eqs. (2) and (3). The results of our findings are presented in Fig. 5. Generally, all the catalysts with mixed oxide support (Y-Z3215) gave a better activity performance with better stability when compared with $5 \mathrm{Ni} / \mathrm{Z}-3215$. This behaviour can be linked to the dominance of $\mathrm{t}-\mathrm{ZrO}_{2}$ phase in the former catalysts relative to the latter, as revealed by the XRD analysis of the catalysts. It has been established that better performance is obtained when zirconia exists mostly in tetragonal phase than in monoclinic phase [36]. Also, the performance of the catalyst could be related to the higher specific surface areas exhibited by the catalysts containing yttria, as shown in Table 1 . The table shows that $5 \mathrm{Ni} / \mathrm{xY}-\mathrm{Z}-3215$ catalysts have higher surface area owing to the addition of yttria which is expected to offer more room for the spread of Ni relative to Z-3215 alone. This will translate into better dispersion of the active metal to increase the number of the active sites. Thus, the better activity of the catalysts (i.e., $5 \mathrm{Ni}-\mathrm{xY}$ Z-3215) could probably be linked to the better dispersion of the active metal on these mixed oxide supports. More so, $\mathrm{CO}_{2}$ conversion is higher than the $\mathrm{CH}_{4}$ counterpart for all catalysts confirming the occurrence of reverse water gas
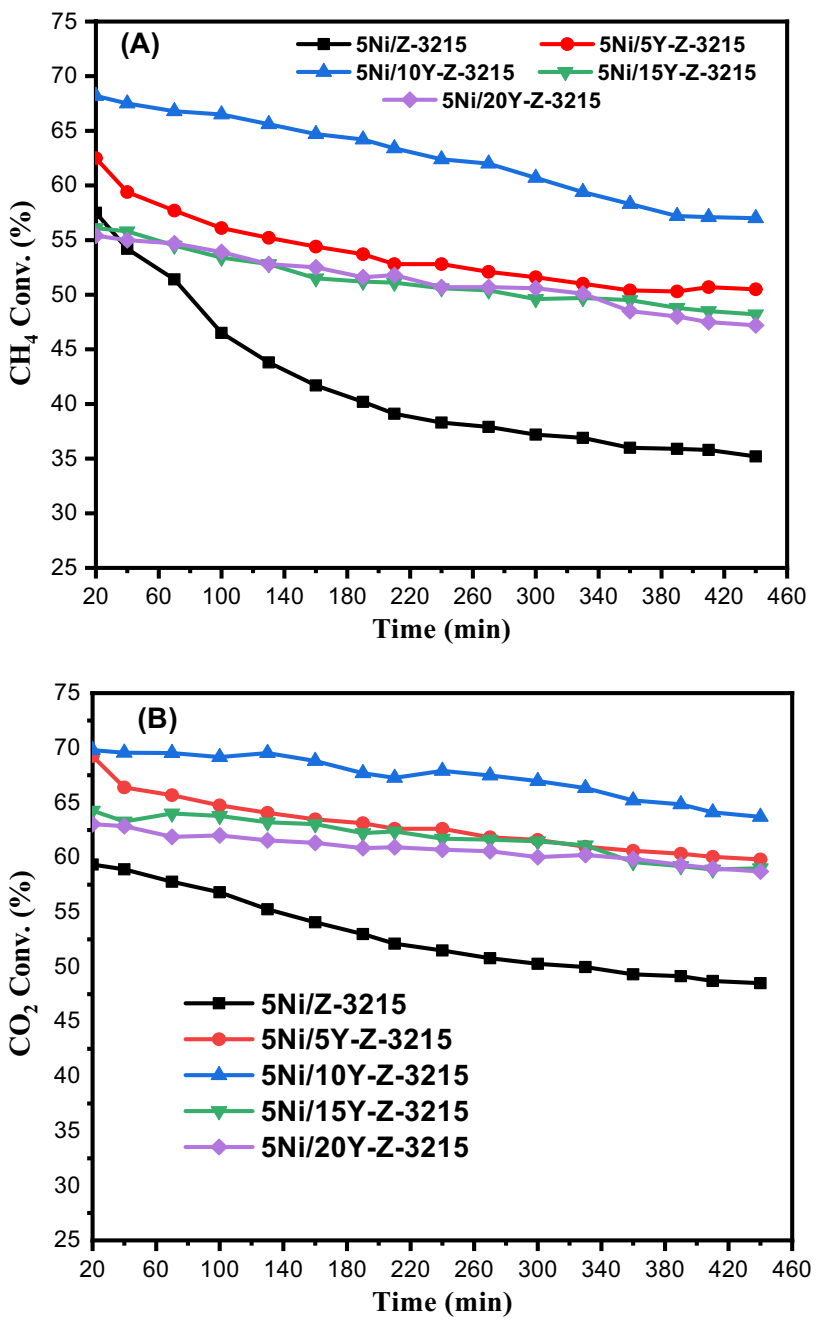

Fig. 5 Catalyst's evaluation in terms of $\mathbf{A ~} \mathbf{C H}_{4}$ and $\mathbf{B ~ C O}$ conversion at $700{ }^{\circ} \mathrm{C}$, atmospheric pressure and $42,000 \mathrm{ml}$ (h. gcat) ${ }^{-1}$ gas space velocity

shift (RWGS) reaction [37]. It can be inferred that the added yttrium oxide favours this shift reaction as the percentage of $\mathrm{CO}_{2}$ conversion increased with increasing the yttria loading.

Furthermore, 5Ni/10Y-Z-3215 had the highest initial feed conversion of about 68 and $70 \%$ for $\mathrm{CH}_{4}$ and $\mathrm{CO}_{2}$, respectively while the $5 \mathrm{Ni} / \mathrm{Z}-3215$ catalyst had the lowest conversion. Moreover, this catalyst suffered a marked decline in activity, just a few minutes after the start of the reaction. The additional oxygen content present in the catalysts containing yttria arguably played a role in the stability of these catalysts by gasifying some quantities of carbon deposits to the oxide of carbon. Table 2 gives a summary of the performance of the catalyst. It was observed that the catalyst performance increased with yttrium oxide addition up until $10 \%$ and then loss of activity started, with little or no difference in the performance of catalysts containing $15 \%$ and $20 \%$ yttria. In the same manner, the catalysts became less prone to deactivation 
Table 2 Catalytic performance of Ni/xY-Z-3215 catalysts (where $\mathrm{x}=0,5,10,15,20)$

\begin{tabular}{lllllll}
\hline Catalyst & \multicolumn{2}{l}{$\mathrm{CH}_{4}$ Conv., $\mathrm{X}_{\mathrm{CH} 4}$} & & \multicolumn{2}{l}{$\mathrm{CO}_{2}$ Conv., $\mathrm{X}_{\mathrm{CO} 2}$} & \multicolumn{2}{c}{$\begin{array}{c}\text { Deactivation } \\
\text { factor (\%) }\end{array}$} \\
\cline { 2 - 3 } & Initial (\%) & Final (\%) & & Initial (\%) & Final (\%) & \\
\hline $5 \mathrm{Ni} / \mathrm{Z}-3215$ & 57.5 & 35.2 & & 57.8 & 48.5 & 38.8 \\
$5 \mathrm{Ni} / 5 \mathrm{Y}-\mathrm{Z}-3215$ & 62.5 & 50.5 & & 69.2 & 59.8 & 19.2 \\
$5 \mathrm{Ni} / 10 \mathrm{Y}-\mathrm{Z}-3215$ & 68.2 & 57.0 & & 69.8 & 63.7 & 16.4 \\
$5 \mathrm{Ni} / 15 \mathrm{Y}-\mathrm{Z}-3215$ & 56.1 & 48.2 & & 64.3 & 59.0 & 14.1 \\
$5 \mathrm{Ni} / 20 \mathrm{Y}-\mathrm{Z}-3215$ & 55.4 & 47.2 & & 63.0 & 58.7 & 14.8 \\
\hline
\end{tabular}

a Deactivation Factor $=\frac{\mathrm{X}_{\mathrm{iCH}_{4}}-\mathrm{X}_{\mathrm{FCH}_{4}}}{\mathrm{X}_{\mathrm{iCH}_{4}}} \times 100 \%$ where $\mathrm{X}_{\mathrm{i}}$ and $\mathrm{X}_{\mathrm{f}}$ represent the initial and final conversion respectively as yttria loading was increased. This can be seen from the percentage relative loss that was calculated from the catalysts' performance (Table 2). 5Ni/Z-3215 suffered the highest activity loss of about $38.8 \%$. As for the yttria containing samples the relative loss reduces with yttria loading.

What's more, the $\mathrm{H}_{2}$ : $\mathrm{CO}$ ratios obtained during the timeon-stream for each of the catalysts are reported in the supplementary file as Figure S1. From the figure, the profiles of all the catalysts are affected by the RWGS reaction i.e., the $\mathrm{H}_{2}$ produced undergoes reaction with $\mathrm{CO}_{2}$ to form more $\mathrm{CO}$. On average the initial $\mathrm{H}_{2} / \mathrm{CO}$ ratio of $5 \mathrm{Ni} / \mathrm{Z}-3215$ is around 1.02 while the final value dropped to about 0.87 showing poor stability. As for the yttria containing samples, they exhibit better stability in their $\mathrm{H}_{2} / \mathrm{CO}$ ratio values.

\subsection{Transmission Electron Microscope (TEM)}

The TEM images of calcined fresh and spent $5 \mathrm{Ni} / 10 \mathrm{Y}-$ Z-3215 are shown in Fig. 6A and B. The dark area represents the coverage of $\mathrm{Ni}$ particles which appears to be
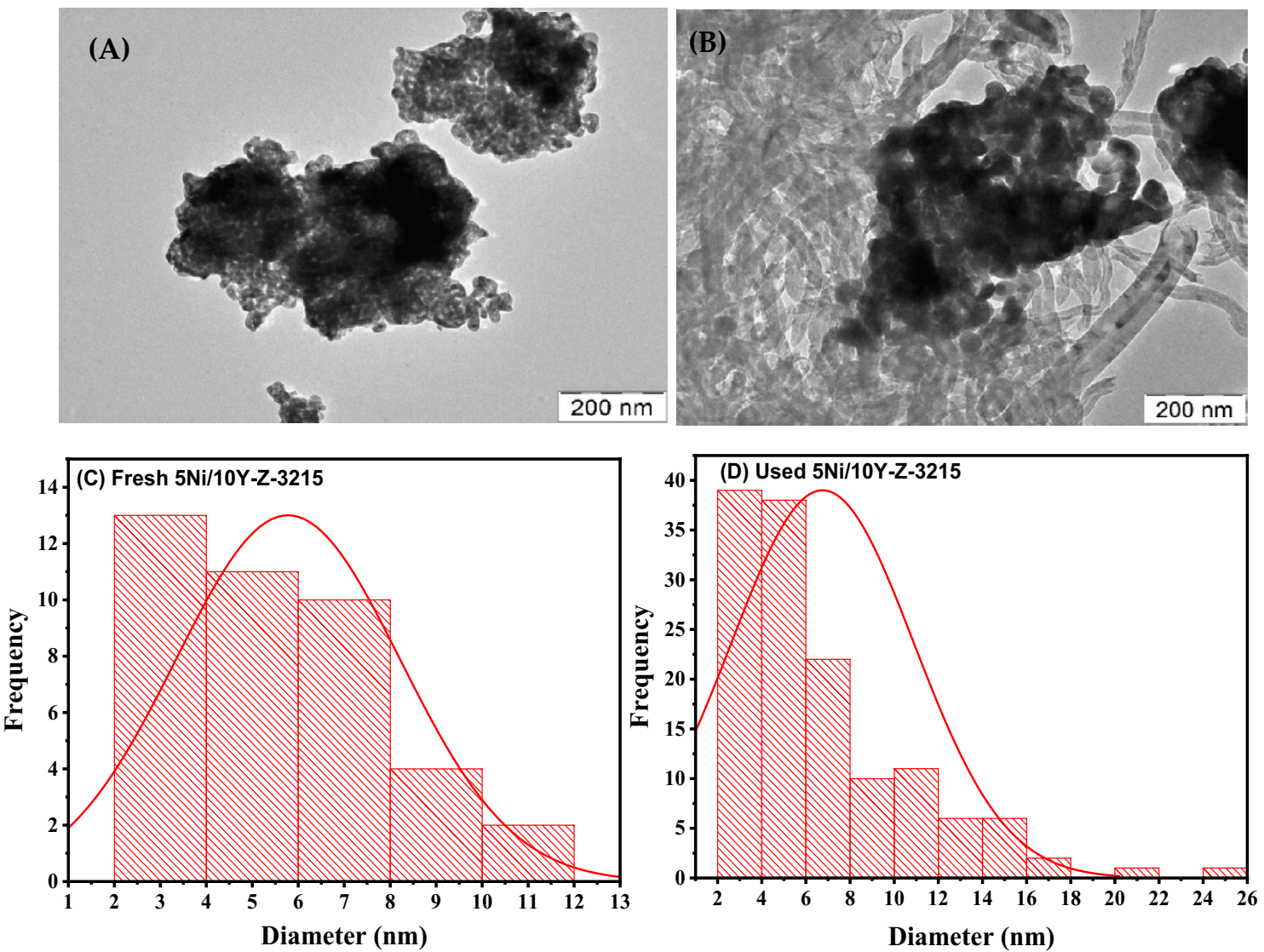

Fig. 6 Transmission electron microscope images for $\mathbf{A}$ fresh and $\mathbf{B}$ used 5Ni/10Y-Z-3215 catalyst sample and the particle size distribution of $\mathbf{C}$ fresh and $\mathbf{D}$ used $5 \mathrm{Ni} / 10 \mathrm{Y}-\mathrm{Z}-3215$ 
homogenously distributed over the support. Figure 6C and D show the particle size distribution of both calcined fresh and spent $5 \mathrm{Ni} / 10 \mathrm{Y}-\mathrm{Z}-3215$. From these figures the particle size of the active metal before reaction, on average, was $5.8 \mathrm{~nm}$ while in the used sample the size changed to $6.7 \mathrm{~nm}$. Consequently, the Ni particles did not undergo sintering at the end of the reaction. As for the used catalyst, there is the presence of carbon in the form of nanotubes with varying diameter.

Yttria modified support have a history of preventing the agglomeration of Ni metal particles and ensuring homogeneity in the distribution of the metal particles. Just as it was reported in a study that compared the performance and characterization of $\mathrm{Ni}$ supported on alumina with that supported on yttria modified alumina [33].

\subsection{Thermogravimetric Analysis (TGA)}

Thermal analysis was performed to determine the quantity of carbon that was deposited on each one of the spent catalyst samples. Figure 7 shows the weight-loss curves of the TG analysis that was conducted in the atmosphere. From this result, weight loss began at around $500{ }^{\circ} \mathrm{C}$ and ended within $770-820^{\circ} \mathrm{C}$ for spent catalysts containing yttria; whereas, the combustion of carbon deposits continued until around $870{ }^{\circ} \mathrm{C}$ for used $5 \mathrm{Ni} / \mathrm{Z}-3215$ catalyst. The latter had the highest amount of carbon deposits of about $53 \%$ while $5 \mathrm{Ni} / 20 \mathrm{Y}-\mathrm{Z}-3215$ had the least weight loss corresponding to $28 \%$ carbon deposits. It was observed that the amount of carbon deposit decreases with the increase in yttria loading owing to the higher oxygen density of yttrium oxide, which could gasify carbon deposits.

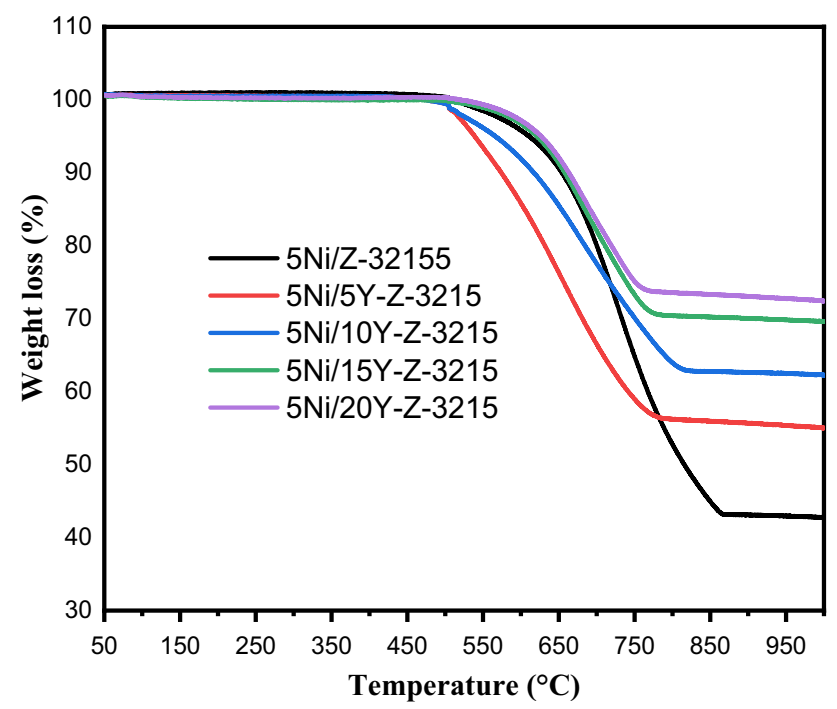

Fig. 7 TGA of spent catalyst samples collected after $7 \mathrm{~h}$. of reaction

\section{Conclusions}

This work investigated the influence of different loadings of yttria (5-20\% at a step of 5\%), being mixed with zirconia as a support, on $\mathrm{CH}_{4}$ reforming with $\mathrm{CO}_{2}$ using $\mathrm{Ni}$ as the active metal. It found that the surface area increased with the addition of yttria. This showed that the yttria offered more room for the dispersion of Ni particles which was possible owing to the difference in the sizes of both particles. All the fresh samples exhibited type IV adsorption-desorption isotherms with $\mathrm{H} 4$ hysteresis. The XRD analysis showed the presence of monoclinic and tetragonal phases of zirconia. Phases of $\mathrm{NiO}$ and yttria were not identified due to their homogenous scatter in the zirconia. The temperature-programmed reduction indicated the effect of the higher loadings of yttria on the reducibility of the catalysts, where decrease in the $\mathrm{H}_{2}$ consumption and a slight shift in the reduction temperature was observed. This has occurred probably due to the formation of $\mathrm{NiYO}_{3}$ species as Ni particles diffused into the pores of the yttria. The performance of the catalysts showed a tremendous increase in activity and stability with the addition of yttrium oxide. This continued up until $10 \%$ yttria loading which has the highest $\mathrm{CH}_{4}$ and $\mathrm{CO}_{2}$ conversion of about 68 and $70 \%$ respectively. Transmission electron microscope of both fresh and used showed a uniform distribution of $\mathrm{Ni}$ particles with no sign of sintering. Carbon in the form of nanotubes with different diameter was observed. The TGA analysis denoted the gasification effect of yttria and that $5 \mathrm{Ni} / \mathrm{Z}-3215$ gave the highest weight loss of about $53 \%$.

Supplementary Information The online version contains supplementary material available at https://doi.org/10.1007/s10562-022-03944-1.

Acknowledgements The authors would like to extend their sincere appreciation to Researchers Supporting Project Number (RSP2021/368), King Saud University, Riyadh, Saudi Arabia

Funding The authors would like to express their sincere appreciation to Researchers Supporting Project Number (RSP-2021/368), King Saud University, Riyadh, Saudi Arabia.

Open Access This article is licensed under a Creative Commons Attribution 4.0 International License, which permits use, sharing, adaptation, distribution and reproduction in any medium or format, as long as you give appropriate credit to the original author(s) and the source, provide a link to the Creative Commons licence, and indicate if changes were made. The images or other third party material in this article are included in the article's Creative Commons licence, unless indicated otherwise in a credit line to the material. If material is not included in the article's Creative Commons licence and your intended use is not permitted by statutory regulation or exceeds the permitted use, you will need to obtain permission directly from the copyright holder. To view a copy of this licence, visit http://creativecommons.org/licenses/by/4.0/. 


\section{References}

1. Pakhare D, Spivey J (2014) A review of dry $\left(\mathrm{CO}_{2}\right)$ reforming of methane over noble metal catalysts. Chem Soc Rev 43:7813-7837

2. Griffin DW, Schultz MA (2012) Fuel and chemical products from biomass syngas: a comparison of gas fermentation to thermochemical conversion routes. Environ Prog Sustain Energy 31:219-224. https://doi.org/10.1002/ep.11613

3. Oemar U, Kathiraser Y, Mo L et al (2016) CO2 reforming of methane over highly active La-promoted Ni supported on SBA15 catalysts: Mechanism and kinetic modelling. Catal Sci Technol 6:1173-1186. https://doi.org/10.1039/c5cy00906e

4. Al-Doghachi FAJ, Islam A, Zainal Z et al (2016) High coke-resistance $\mathrm{Pt} / \mathrm{Mg} 1-\mathrm{xNixO}$ catalyst for dry reforming of methane. PLoS ONE 11:e0145862. https://doi.org/10.1371/journal.pone.0145862

5. Xu L, Wang F, Chen M et al (2017) Alkaline-promoted Ni based ordered mesoporous catalysts with enhanced low-temperature catalytic activity toward $\mathrm{CO}_{2}$ methanation. RSC Adv 7:18199-18210. https://doi.org/10.1039/c7ra01673e

6. Abdullah B, Abd Ghani NA, Vo DVN (2017) Recent advances in dry reforming of methane over Ni-based catalysts. J Clean Prod 162:170-185

7. Whang HS, Choi MS, Lim J et al (2017) Enhanced activity and durability of Ru catalyst dispersed on zirconia for dry reforming of methane. Catal Today 293-294:122-128. https://doi.org/10.1016/j. cattod.2016.12.034

8. Ibrahim AA, Amin A, Al-Fatesh AS et al (2019) Nanosized Ni/ SBA-15 catalysts for $\mathrm{CO}_{2}$ reforming of $\mathrm{CH}_{4}$. Appl Sci. https://doi. org/10.3390/app9091926

9. Rostrup-Nielsen J, Trimm DL (1977) Mechanisms of carbon formation on nickel-containing catalysts. J Catal 48:155-165. https://doi. org/10.1016/0021-9517(77)90087-2

10. Han JW, Kim C, Park JS, Lee H (2014) Highly coke-resistant Ni nanoparticle catalysts with minimal sintering in dry reforming of methane. Chemsuschem 7:451-456. https://doi.org/10.1002/cssc. 201301134

11. Gould TD, Izar A, Weimer AW et al (2014) Stabilizing Ni catalysts by molecular layer deposition for harsh, dry reforming conditions. ACS Catal 4:2714-2717. https://doi.org/10.1021/cs500809w

12. Fakeeha AH, Bagabas AA, Lanre MS et al (2020) Catalytic performance of metal oxides promoted nickel catalysts supported on mesoporous $\gamma$-Alumina in dry reforming of methane. Processes 8:522. https://doi.org/10.3390/PR8050522

13. Al-Fatesh AS, Arafat Y, Kasim SO et al (2020) In situ auto-gasification of coke deposits over a novel Ni-Ce/W-Zr catalyst by sequential generation of oxygen vacancies for remarkably stable syngas production via $\mathrm{CO}_{2}$-reforming of methane. Appl Catal B Environ 280:119445. https://doi.org/10.1016/j.apcatb.2020.119445

14. Taylor KA, Paskewitz SM, Copeland RS et al (1993) Comparison of two ribosomal DNA-based methods for differentiating members of the Anopheles gambiae complex (Diptera: Culicidae). J Med Entomol 30:457-461. https://doi.org/10.1093/jmedent/30.2.457

15. Craciun R, Shereck B, Gorte RJ (1998) Kinetic studies of methane steam reforming on ceria-supported Pd. Catal Lett 51:149-153. https://doi.org/10.1023/a:1019022009310

16. Smirnov MY, Graham GW (2001) Pd oxidation under UHV in a model Pd/ceria-zirconia catalyst. Catal Lett 72:39-44. https://doi. org/10.1023/A:1009092005849

17. Da Silva ALM, Den Breejen JP, Mattos LV et al (2014) Cobalt particle size effects on catalytic performance for ethanol steam reforming — smaller is better. J Catal 318:67-74. https://doi.org/10.1016/j. jcat.2014.07.020

18. Haller GL, Resasco DE (1989) Metal-support interaction: group VIII metals and reducible oxides. Adv Catal 36:173-235. https://doi.org/ 10.1016/S0360-0564(08)60018-8
19. Abdel-Mageed AM, Widmann D, Olesen SE et al (2015) Selective $\mathrm{CO}$ methanation on $\mathrm{Ru} / \mathrm{TiO}_{2}$ catalysts: role and influence of metalsupport interactions. ACS Catal 5:6753-6763. https://doi.org/10. 1021/acscatal.5b01520

20. Cargnello M, Fornasiero P, Gorte RJ (2012) Opportunities for tailoring catalytic properties through metal-support interactions. Catal Lett 142:1043-1048

21. Han JW, Park JS, Choi MS, Lee H (2017) Uncoupling the size and support effects of Ni catalysts for dry reforming of methane. Appl Catal B Environ 203:625-632. https://doi.org/10.1016/j.apcatb. 2016.10.069

22. Kambolis A, Matralis H, Trovarelli A, Papadopoulou C (2010) Ni/ $\mathrm{CeO} 2-\mathrm{ZrO}_{2}$ catalysts for the dry reforming of methane. Appl Catal A Gen 377:16-26. https://doi.org/10.1016/J.APCATA.2010.01.013

23. Baraka S, Bouearan K, Caner L, et al (2021) Catalytic performances of natural Ni-bearing clay minerals for production of syngas from dry reforming of methane. $\mathrm{J} \mathrm{CO}_{2}$ Util 52:101696. https://doi.org/10. 1016/J.JCOU.2021.101696

24. Ding H, Virkar AV, Liu F (2012) Defect configuration and phase stability of cubic versus tetragonal yttria-stabilized zirconia. Solid State Ionics 215:16-23. https://doi.org/10.1016/J.SSI.2012.03.014

25. Bahari MB, Setiabudi HD, Duy Nguyen T et al (2020) Insight into the influence of rare-earth promoter $\left(\mathrm{CeO}_{2}, \mathrm{La}_{2} \mathrm{O}_{3}, \mathrm{Y}_{2} \mathrm{O}_{3}\right.$, and $\mathrm{Sm}_{2} \mathrm{O}_{3}$ ) addition toward methane dry reforming over $\mathrm{Co} /$ mesoporous alumina catalysts. Chem Eng Sci. https://doi.org/10. 1016/J.CES.2020.115967

26. Wang $\mathrm{Y}$, Wang $\mathrm{L}$, Gan $\mathrm{N}$ et al (2014) Evaluation of $\mathrm{Ni} / \mathrm{Y}_{2} \mathrm{O}_{3} / \mathrm{Al}_{2} \mathrm{O}_{3}$ catalysts for hydrogen production by autothermal reforming of methane. Int J Hydrogen Energy 39:10971-10979. https://doi.org/ 10.1016/j.ijhydene.2014.05.074

27. Hu X, Yang J, Sun W et al (2020) Y-Zr-O solid solution supported Ni-based catalysts for hydrogen production via auto-thermal reforming of acetic acid. Appl Catal B. https://doi.org/10.1016/j.apcatb. 2020.119264

28. Sudarsanam P, Hillary B, Deepa DK et al (2015) Highly efficient cerium dioxide nanocube-based catalysts for low temperature diesel soot oxidation: the cooperative effect of cerium- and cobalt-oxides. Catal Sci Technol 5:3496-3500. https://doi.org/10.1039/c5cy00525f

29. Leofanti G, Padovan M, Tozzola G, Venturelli B (1998) Surface area and pore texture of catalysts. Catal Today 41:207-219. https://doi. org/10.1016/S0920-5861(98)00050-9

30. Sotomayor FJ, Cychosz KA, Thommes M (2018) Characterization of micro/mesoporous materials by physisorption: concepts and case studies. Acc Mater Surf Res 3(2):34-50

31. Barroso-Quiroga MM, Castro-Luna AE (2010) Catalytic activity and effect of modifiers on Ni-based catalysts for the dry reforming of methane. Int J Hydrogen Energy 35:6052-6056. https://doi.org/ 10.1016/j.ijhydene.2009.12.073

32. Sun GB, Hidajat K, Wu XS, Kawi S (2008) A crucial role of surface oxygen mobility on nanocrystalline $\mathrm{Y}_{2} \mathrm{O}_{3}$ support for oxidative steam reforming of ethanol to hydrogen over $\mathrm{Ni} / \mathrm{Y}_{2} \mathrm{O}_{3}$ catalysts. Appl Catal B 81:303-312. https://doi.org/10.1016/j.apcatb.2007.12. 021

33. Damyanova S, Shtereva I, Pawelec B et al (2020) Characterization of none and yttrium-modified Ni-based catalysts for dry reforming of methane. Appl Catal B 278:119335. https://doi.org/10.1016/j. apcatb.2020.119335

34. Li G, Hu L, Hill JM (2006) Comparison of reducibility and stability of alumina-supported $\mathrm{Ni}$ catalysts prepared by impregnation and co-precipitation. Appl Catal A 301:16-24. https://doi.org/10.1016/j. apcata.2005.11.013

35. Ruckenstein $\mathrm{E}, \mathrm{Hu} \mathrm{YH}$ (1996) Role of support in $\mathrm{CO}_{2}$ reforming of $\mathrm{CH}_{4}$ to syngas over Ni catalysts. J Catal 162:230-238. https://doi. org/10.1006/jcat.1996.0280

36. Al-Fatesh AS, Arafat Y, Ibrahim AA et al (2019) Catalytic behaviour of ce-doped ni systems supported on stabilized zirconia under dry 
reforming conditions. Catalysts 9:473. https://doi.org/10.3390/catal 9050473

37. Bradford MCJ, Vannice MA (1996) Catalytic reforming of methane with carbon dioxide over nickel catalysts I. Catalyst characterization and activity. Appl Catal A 142:73-96. https://doi.org/10.1016/0926860X(96)00065-8
Publisher's Note Springer Nature remains neutral with regard to jurisdictional claims in published maps and institutional affiliations. 